NORDISK MUSEOLOGI $1999 \cdot 2$, S. 55-64

\title{
LOCAL IDENTITY IN THE PROCESS OF GLOBALISATION THE ECOMUSEUM QUESTIONED
}

«FINDING THE SIGNS OF A WORLD REMATERIALISATION» ${ }^{1}$

\section{Mathilde Bellaigue}

Ten years' (1976-1986) experience of working in what was, during the seventies and first half of the eighties, the most famous and forward-looking of the then existing ecomuseums, the Ecomuseum of Le Creusot-Montceau-les-Mines, its transformation into a traditional museum of technique in 1986, the very similar fate of the Ecomuseum of Haute-Beauce in Quebec (1996), raises the need to reconsider the phenomenon of the ecomuseum both in the current cultural policies of western countries and in the globalisation process.

Many people today ask: do you still believe in ecomuseums? Is there a future for them?

THE EVOLUTION OF THE ECOMUSEUM PHENOMENON FROM 1970 - THE EXAMPLE OF LE CREUSOT AS AN ARCHETYPE

Today in France, the situation in the field of ecomuseums is not without ambiguities, due both to the evolution of mentalities since its inception and to a different public approach. In fact, volunteers in the cultural field are no longer in fashion, and enthusiasm for local participation together with lively associations, which were so marked after 1968, have declined. With the arrival of Jack Lang in 1981, the policy of the Ministry of Culture has favoured both the rentability of culture and the spectacular side of projects...

Since that period, in France, the number of ecomuseums and the so-called "community museums» (everything that is not a beaux-arts and natural history museum) has expanded to around 50, including some institutions rather removed from the initial ideas.

Abroad on the other hand, some projects of the same kind, often inspired by Le Creusot, still adhere rather closely to its original ideas.

Basic principles :

Space - time - people - heritage

Concerning the entity ecomuseum, one cannot speak of a theory as the foundation 
56 of practice, but rather of some basic principles that justify its existence, such as the importance given to space and time, the use and preservation of heritage as a tool for the development of the local population, the idea that the latter is the responsible owner of its history and cultural development. Theory takes form progressively with practice; the existence of any ecomuseum rests on a permanent interplay between the two, showing, if required, that such a museum should not become an institution, but rather needs to develop as an organic project constantly evolving according to living reality. That is why it either does not fit in administrative cultural categories or, if successful, it becomes an object of political covetousness.

The starting points in Le Creusot were globality (Marcel Mauss: the "total social facts), locality and also artistic model implying the acknowledgement of contradictions: heritage/creation, reality/imagining, Culture/cultures, identity/openness. These constituted the core of ecomuseology as elaborated from experience and principles. From those paradigms, numerous actions were to take shape, always involving as researchers both the scientific community and the local community, according to the needs and desires of the latter, using and valuing its mental and physical heritage, expressing and explaining it in exhibitions, symposiums and shared training.

Daily practice requires from its professional actors an investment which, though not essentially different from a volunteer attitude, has to respect the necessary distance from the community's private stories, hesitations and refusals. But at the same time, it has to unveil hidden aspects of history and reminiscences, and arouse consciousness. Any ecomuseal program has to be built on such a complex and delicate balance if it is to allow sustainable human relations.

\section{Process and realisations}

The material to be studied, elucidated and communicated were the traces of history and daily life, in the whole environment. So the museum, if there was to be a museum, normally had to be inside and outside walls, decentralised into some permanent «antennas». Those were created and worked by local people with the help of one museum professional, around their own heritage, their own craft and knowhow, their own memory and history to be told. Such action was not easy for them. The great industrial adventure of the 19th and 20th centuries had made them famous for the quality of their skills with metals and their technical prowess. But at the same time they had been imposed on, through the paternalist system, with its requirement for absolute submission, lack of any freedom of opinion and of trade union action. This they resented, more or less consciously. Traces of the past remained everywhere, material or memorial. Everything had to be collected, studied and elucidated.

But what was to be said, how, and by whom? In short : which image for which identity?

Part of the process, or even the deontology, demanded the precise identification and inventory of a territory, of its inhabitants, of their needs and desires, of the actions to be initiated with them, they being the real owners of their history and memory, and the actors in their present. 
For these reasons, establishing an ecomuseum differed completely from establishing a classical museum. No collections existed at the beginning. Reality was the media, the message itself from which immaterial testimonies made known their importance. Little by little, according to the rythm of remembrance and desire, objects came to the museum, either given or lent, but each with its own background. The first approach could only be sensitive and emotional, leading subsequently to intelligent comprehension and lucidity for the future.

\section{Ethics}

Today, if we no longer want the museum to be merely a repository, a conservatory of dead things - because we do not believe in them anymore - it is not only the institution we have to change, we must also change ourselves, the museologists. The new type of museologist is not simply a curator, a researcher, he is also someone in the field, permanently related to the local people, involving himself in something that is more than just a profession. Actors in social life, servants to a community and possible agents of its development, we must be attentive to the needs and requests of that community.

Four large themes are currently prominent in our society: social integration, identities vs nationalisms, safeguarding of the environment, and knowledge of the technical culture, to prevent its overwhelming us. In such a context, the mission of the ecomuseum is to develop the community's critical consciousness.

Actually the ecomuseum is the community itself, lucid and active on its own territory, opened to other communities.

\section{Difficulties and dangers}

The following have to be stressed:

1. It is difficult for anyone to live and to study their own culture simultaneously.

2. Studying one's own identity may exclude openness to other groups.

3. The balance between preservation and innovation and development is delicate (for instance one cannot "freeze» a city which needs to develop). Here artists may play an interesting part.

4. When unveiling memory, things have to be said but some silences have to be respected.

5. The growth of the ecomuseum and its staff has to be controlled as well as its success, otherwise it will be coveted as a local political instrument.

6. The criterion of such a museum is not financial rentability. True gain is the development of mentalities and consciousness (which the politicians often regard as ultimately dangerous...)

\section{GLOBALISATION \\ «THE ERA OF DISPARITION»}

\section{Loss of landmarks}

As museologists we are used to dividing time into periods, civilisations, history, attempting to deal with the genesis of changes. Globalised time belongs to the world, not just to the territory or the period: it is instantaneous and ubiquitous. Today speed is the most important factor because it gives power. As Virilio says "speed is the milieu" ${ }^{2}$. Homo economicus possesses instantaneous instruments: Concorde, Internet, tele-meetings, mobile telephones etc.

In contrast "inhabiting the time», as expressed so beautifully by Kanak Jean- 
Marie Tjibaou, is an art we have lost ${ }^{3}$.

The current perception of time imposes a new perception of space: space is somehow denied because the information and the decision can be instantaneously everywhere. (However, I cannot forget having seen at the opening exhibition of the Bibliothèque de France a manuscript of the "De Imago Mundi" which belonged to Christopher Colombus (kept in Seville). On this document, annotated in his own hand, were words to the effect that the earth is not so big...)

Paradoxically, those who have a strong consciousness of the true dimension of time and space today are people without roots - exiles, emigrants, people who have not only lost their territory, but everything else. Experiencing such a loss certainly gives a new meaning to time, which will most probably be in the form of waiting, and longing for a long time... They do not belong anymore to anywhere, and often nothing belongs anymore to them, except in their memory.

Further weakening our sense of the solid world around us, we nowadays welcome virtuality - it is the reality of the well-off, via Internet, numerics, holography. In fact the virtual has prevailed over the real: physical presence is no longer necessary thanks to the new technologies for distant communication. We recognise that in these ways "absent people "can become» present». One example could be of some endangered communities, such as the Chiapas Indians, making themselves heard through the Internet to let the world know of their issues. But will not this immaterial, ghostly, disembodied presence sooner or later cause the perversion of human relations?
It is said that we live in the «civilisation of images" and it is true: images often replace objects and museums can use this for themselves. And this can be a positive element: just as a document, the image, is often a representation of reality. But an image can also be an artwork inspired by and inspiring creation (consider some photos by Cartier-Bresson, Doisneau, Sudek, Kertesz and others). So it happens that looking at an image comes to require the same skills as looking at an object: the same capacity to read the meaning thoroughly, to appreciate the esthetics, to feel the personality of the author: here we talk no more of «disparition» but, on the contrary, of an added presence.

Mass media value both the virtual and the image. Though we have never talked so much about communication the substance of communication disappears. This illusion of the human sciences has become institutionalised, professionalised. Have we lost our direct, spontaneous, instinctive means of communication? The instruments of the media are "quantitative therefore coming from power. TV presenters, mediators, journalists simplify to be understood, in fact, they do not say anything anymore. They say words without any weight, empty words. In this way all the information system does is to destroy the subtlety of one to one relationships. Wanting to talk to everybody at the same time, they do not talk to anybody. Our world just wants to know what is happening, it creates more and more sophisticated files, dealt with by computers able to store more and more data. In this way the information system only does away with reality and quality». ${ }^{4}$

These modifications and losses also 
occur in the field of material life: since the Second World War and the acceleration of industry, we have seen the universal standardisation of everyday objects. Material goods are homogenised. It should have been for peoples' material benefit, and though this is sometimes the case, it is always with the loss of material culture and cultural identity.

So if our familiar markers disappear periodised time, familiar landscapes, real communication, unique objects - where should we look for identity? Where are our material traces? Where lies memory?

\section{Does the word "community" have a meaning today?}

The most tragic result of wars between neighbouring populations is the destruction of ethnic or religious communities (Bosnia, Kosovo, Rwanda, Kurds, etc.). each war being generally preceded by the destruction of their material heritage, of their symbols, as a prelude to the destruction of the people. Memory is essential to survival.

In France the rise of the extreme rightwing, with its hostility towards immigrants, the problem of suburban ghettos, plus unemployment, accentuate a new refusal to recognise or negotiate with heterogeneity, a denial of non-French cultures within our borders, resulting in violence and damage.

Abroad we have seen the greedy massacre of small groups previously living in balance with their environment, with their lifestyle, their local resources, e.g. Amazonian Yanomamis, Native Americans on reservations, Australian Aboriginals. As Edgar Morin puts it, "small civilisations are being destroyed and we do not know how to preserve them... We cannot lock them away in a zoo to protect them and if we open them in trying to integrate them we risk their disintegration [...] We felt we were right because we thought our arguments were logical but also totally abstract because we thought all truth relied on science. We ignored for instance that a profound knowledge had been acquired in every country's populations» ${ }^{5}$. It is not only people we are decimating, territories we are destroying, but also some ancient and precious wisdoms are also disappearing for ever.

So how could we define a "community" today, so that it is not defensive, or introverted, or exclusive...? Perhaps we may be able to find a more positive meaning for this word, widening it to include all the people of our common planet.

\section{Identity and memory}

Nonetheless it seems that the more mass culture threatens to take over life, and to «integrate» communities, the more people feel the need to be specially different, to belong somewhere particular: thus in big cities foreign communities reconstitute themselves and maintain living traditions, rites, their mother tongue, recreating some local way of life within the body of the dominant society. This active attitude both arises from and fosters collective memory. How does it form when immigrants have gathered in successive waves? It is pieced together out of the sum of individual memories whose roots are the same through the diversity of objects life has released, of places and life experiences, of interpretation through common knowledge and beliefs. But other cases are similar, such as youth groups, special interest 
groups and so on.

We should also talk about those "without memory», heirs of the uncommemorated, of people formerly considered shameful, unworthy. In 1998 in France we celebrated the 150th anniversary of the abolition of slavery. Some critics pointed out that the commemoration was distorted with emphasis on the righteousness of the abolition law rather than on the terrible circumstances surrounding the slave trade and their resistance that had finally led to their freedom. Never before had slavery a crime against humanity - been officially recognised. For instance, our museums had kept silent about it until the $90^{\prime} \mathrm{s}^{6}$. In another misunderstanding, we sometimes believe that the memory of slaves' descendants comes from far away original Africa. But as Patrick Chamoiseau, a Martinican poet and himself a descendant of slaves, says (and feels), the starting point of the Creole identity «is not original Africa, but the hold of a ship, the place of collapse. Going down the hold, we did not go into another world but into another life where gods and certainties had to be reinvented, everything had to be redone»?. He calls this memory change "genesical death, both symbolic and concrete». It is as though another memory was born out of the ruins of a preceding one. We can see the same reaction in Primo Levi's interviews and books after his return from Auschwitz...

So when we think that through a commemoration, a memorial, an official "memory's duty», we honour with dignity the heirs of the past, it is true that we recognise a historical event and that it stirs the public conscience, but this happens anonymously. The faces of the actors blend and names disappear. That is why some artists' works seem exemplary in their effort to reject official anonymity. Examples of this are the work of Jochen Gerz in the small Périgord village of Biron, France, where he inscribes on the memorial to the dead of the Great War the inhabitants' individual statements; and the obsessive work of Christian Boltanski concerning the children of an old Belgian mine: in an exhibition he lines up their humble photographs and their names from top to bottom of weakly lit underground walls. When we see them we cannot avoid being moved, feeling a certain tenderness for those who, in their tragedy, bear a name.

\section{IIN SEARCH OF "A WORLD REMATERIALISATION»}

A possible way forward for the ecomuseum: widening its scope...

Paul Virilio's phrase could be the motto of third millennium museums. Resisting dispersion, dilution, upset identities, disguised or denied reminiscences - in short "disparition» - what can museums do with their humble means? Our answer must be to find our culture's signs or markers and give them a sensitive form so that their sense can be perceived. Is not that exactly the museums' duty?

Virilio suggests the following means to achieve this end, which he calls «rematerialisation".

\section{"Be present here and now"}

Totally opposed to the "disparition" caused by aspects of globalisation, the advantage of the ecomuseum is that it takes into account a territory within its limits, its 
population with its material culture, "the signs of history, visible things which are so much a part of the physical and mental landscapes that they are inseparable. The main objective is to throw light on them; a revealing light which will enable us to see what habits and routine hide»" ${ }^{8}$. Turning attention to the "here" and "now» is educating the gaze upon the object, even in its everyday banality, upon traces in a landscape, in a city. This gaze upon space, upon the organisation of the environment, upon the links between people in society, has a museal translation through the explanation of a territory, of its ecological and social systems as an organic whole and not in a universal anonymity. It is an interdisciplinary work connecting earth and human sciences in such a way that artworks, objects, archives, monuments, places are signs presented by the museum.

Every community's museum is based on two sorts of history: a past perceived by people, comprising reminiscences of high points in experience, relying on sensitive aids such as sites of life, objects, habits and traditions; and on the other hand historical research which corrects, sheds light on the sense of what has been experienced; it is not a matter of reconstructing but of translating. This is not always easy and we should recognise that throwing light on history may sometimes hurt the emotional sides of memory. I have mentioned elsewhere $^{9}$ the desire of Le Creusot's local councillors to erase most traces of the old Schneider factory, a place of work and also of enslavement, but also a memorial to social struggles. It is the obsession with a past that does not pass away.
"The near and the far"

The ecomuseum approach is based on the community's "near», but it can also make understood "the far", the strange, the other. This approach is effective because it does not close down into a fixed identity (what Alfred Grosser calls «abusive identities ${ }^{10}$ whose presence stirs up nationalism, racism, etc.) but on the contrary opens up all means of comparison with similar situations.

Thus the ecomuseum becomes the archetype of social places for meetings, for comparing experiences, for common elucidation resulting in/or from exhibitions. Is such remembering together a maker of collective memory? Or is it just a companionship movement that risks withdrawal, introversion? «Freeing without dropping out, that is keeping a critical distance towards any group even privileged ones, but without eliminating different integrations without which man is asocial and useless to others", this is the teaching recommended by Alfred Grosser ${ }^{11}$. That is the measure to aim at.

There is a considerable distance from the object observed in the museum to the one who observes it, for two reasons: one because the museum presents a community's vision not shared by the visitor, and we remind ourselves of the paper by Poka Laenui (Hawai) about the Bishop Museum Exhibition "The Hawaians», in which the history of Hawai was told only from the conquest of the isle by Cook; Laenui answers to this with some humour: "Cook did not discover us. We knew, long before he was conceived, who and where we were.» ${ }^{12}$ Secondly this huge distance between the one who remembers and what is to be remembered may also exist 
62 because the objects come from the past or the geographical distant.

The museum has therefore (not without risk) this strange and double power: to bring us closer to a time or a space sometimes forgotten, or unknown, but also to make us realise the distance separating us, now, from them, there and then. This distance generates questioning, imagination, dreaming and opens up consciousness.

\section{"From memory to timelessness"}

The object perceived in that way emerges from time and space. It was the sign of a former or distant reality, and all of a sudden it becomes the symbol of a universal truth. It may no longer be a token of any memory.

We must therefore be careful how we treat each object: it is not a matter of accumulating collections but of giving the greatest attention to the objects' roles as signs so as to avoid serious misinterpretations. One example "a contrario" occurred recently in the new Egyptian Antiquities Department, at the Louvre Museum: the curator placed amongst other objects, in a window display, the mummified body of a reclining man, naked; a week after the opening of the department the staff casually threw a loincloth over him. Had they recognised humanity in that "object"? But clothing was not the solution to the problem, which was more about the trivial treatment of that "object», the mockery of death, the indifference to what the museum is supposed to evoke, namely Egyptian rites of embalming and burying which, in their mystery, respected and finally hid to human eyes the flesh of the one who has passed away. The man lying in our gaze amongst varied objects (which did not even belong to his tomb) does not give us any information about his life, his time, his death. He has no identity, no memory. And more outrageously still, because of the presentation's insensitivity, he is of no importance...

Today the contribution of exact sciences to the knowledge of objects and works of art is a relatively new dimension which will certainly be developed in the museums in the future. Materials science, as applied in the Research Laboratory of the French Museums, penetrates the heart of matter, identifies it, reveals its origin and the objects' exchange networks from one society to another; the same sciences throw light on artists' techniques, their pentimenti, their gestures of creation ${ }^{13}$. I mention it here because it adds a wider dimension of space and time to the memory opened up by the museum and because the "so far, so near» we are discovering is a new side of the suggested dream.

That is why the museum has a strange alchemy where the object, testimony of a precise moment and place, takes on a timeless, universal dimension through which we have access to the world. As Virilio writes, "measuring the world is our freedom. Knowing that the world around us is enormous, realising it, even if we do not practise that world, is an element of the freedom and greatness of $\operatorname{man}\rangle^{14}$. Remember Colombus...

Such a view does not change fundamentally the philosophy of the ecomuseum whose method and ethics remain linked to its territory and its population's development, but it stresses still more the absolute necessity for it to keep in perspective the fact that its territory belongs to the planet and its population to humanity. Such a 
perspective may guarantee that it makes the best of globalisation and not the worst.

\section{CONCLUSION}

The museum must help the community undertake not so much a duty of memory as a work of memory, which also means a work of forgetting because the work of memory is a "duty of truth" ${ }^{15}$. The function of the museum is to awake consciousness in several dimensions:

Consciousness of time: knowing what links us to our origins, to our temporality (duration). "Looking at the past is not a backward-looking attitude, it is to acknowledge its nourishing sense, the base of our memory. Being unconscious of time makes us unable to imagine the future». ${ }^{16}$

Consciousness of diversity: the refusal of homogenisation and acknowledgement of differences gives true dimensions to the world and humanity. It opens up a dialogue.

In the globalising world, communities find it increasingly difficult to survive, as expressed in the statement of the Indian chief Seatle to the President of the United States in 1894: "This fate is mysterious for us, because we cannot understand why all the buffalos are massacred, wild horses domesticated, the forest's secret places full of the smell of so many men, and the view of the beautiful hills soiled by the talking wires. Where are the deep thickets? They are gone. Where is the eagle? Gone. It is the end of life and the beginning of survival».

Consciousness of the eternal community of humanity: the survival problem is on the scale of humanity. «Our histories from now on are total and largely shared, and our responsibilities, because of this, diffused [...] It is we who must think of the poetics of this globalisation. I mean poetics where it concerns the inside of things and not their shape. As long as man has not accepted a new conception of his identity, slavery, genocide will remain without answer. Cultures, people of the world must be intimately persuaded that they can have exchanges with their neighbour and, through the imagination and the sensitivity they propose, change the neighbours without disintegrating. Without risking dilution. [...] We have a job: contribute to this stirring of the world's imagination and sensitivity which will allow us to really work together». ${ }^{17}$

If the "end of life and the beginning of survival" are not to appear like a museum caricature, our job as museologists is to show to humanity that it owns its identity, its memory, its capacity for survival. For, if museums deal with memory, they do it to bear testimony to man's progress and failures, to throw light on them, to prove man can survive in spite of everything, that we are able to invent, create. In one word, the museum is concerned with human dignity, whichever community we belong to.

\section{NOTES}

1. Titles are taken from Paul Virilio, Cybermonáe, la politique du pire. Paris, Textuel publ., Le Seuil diff., 1996.

2. Op. cit.

3. Jean-Marie Tjibaou, La Présence Kanak. Paris, Odile Jacob publish. 1996. 
64 4. Marcel Evrard, 1983, unpublished.

5. Edgar Morin in Les Nouvelles de Survival International, printemps 1997, p. 11.

6. C.A. Celius, ICOFOM Study Series 27, "Museology and Memory", p. 182-189.

ICOFOM Paris, 1998.

7. Le Monde, 24 avril 1998.

8. Marcel Evrard, 1983, unpublished.

9. ICOFOM Study Series 27, «Museology and

Memory", p. 178. ICOFOM Paris, 1998.

10. Le Monde, 28 janvier 1994.

11. Op. cit.

12. ICOFOM Study Series 10, "Museology and Identity» ICOFOM, Buenos Aires, 1986.

13. See TECHNE - La science au service de l'art et des civilisations, the magazine of the Laboratoire de recherche des musées de France. Paris, RMN publisher.

14. Op. cit.

15. Paul Ricoeur, Leçons au Collège de philosophie, Paris, 1996.

16. M. Evrard, 1983, unpublished.

17. Le Monde, 1998. E. Glissant is a Creole philosopher and poet.

Mathilde Bellagiue was first assistant to Marcel Evrard, foundator and director of the Ecomuseum of the Community Le Creusot-Montceau-les-Mines, then director. Later in charge of the scientific publishing of the Research Laboratory of the French Museums (Louvre). Creator and editor of the review TECHNE. Numerous museology articles in French and foreign magazines, participation in collective books. Member of the board of the International Committee for Museology of ICOM (ICOFOM, 1983-1998).

Adr. 44 Rue de Babylon, 75007 Paris, France, Fax: +33-1 45557301

email:mathilde.bellaigue@wanadoo.fr 